\section{Commentary: If your pants are too loose, use both belt and suspenders}

\author{
Ruggero De Paulis, MD
}

The treatment of mitral valve insufficiency has made enormous progress in the last decades, and certainly a wide variety of techniques have been described since Carpentier first introduced the basic concepts of the "French correction." The standard technique was mainly based on the quadrangular resection of the posterior leaflet and several associated and additional procedural steps such as leaflet sliding, chordal shortening and/or transposition, closure of indentation, and commissures. For many years, the execution of this procedure has remained in the hand of few experienced centers or dexterous surgeons. With time, mitral valve repair has been approached by most centers and has become an important part of the armamentarium of the cardiac surgeon.

Certainly, a major paradigm shift from the classical way of repair was introduced after the good performance of polytetrafluoroethylene (PTFE) sutures tested in sheep, by Vetter and colleagues ${ }^{2}$ back in 1985 . The use of PTFE sutures has since greatly facilitated the execution and the reproducibility of mitral valve repair, invariably contributing to an increase in the success rate and in the long-term durability of the results. ${ }^{3}$ To this extent, the use of PTFE chordae has made possible a less aggressive leaflet resection of the prolapsing segments in the quest for a more physiological approach. ${ }^{4}$ Last but not least, the possibility of combining a standard resection with the use of PTFE chordae has certainly facilitated the steps toward a minimally invasive surgical access.

In this issue of the Journal, David and colleagues ${ }^{5}$ report their long-term experience of chordal replacement with ePTFE sutures in a challenging group of patients with bileaflet prolapse. The great, striking high incidence of patients with true bileaflet prolapse, usually quite rare, can only be explained by a selection process due to the exclusive referral to the author David of the majority of these complex

From the Department of Cardiac Surgery, European Hospital, Rome, Italy.

Disclosures: Author has nothing to disclose with regard to commercial support.

Received for publication Aug 30, 2019; revisions received Aug 30, 2019; accepted for publication Aug 30, 2019; available ahead of print Sept 21, 2019.

Address for reprints: Ruggero De Paulis, MD, Department of Cardiac Surgery, European Hospital, Via Portuense 700, 00149 Rome, Italy (E-mail: rdepaulis58@gmail. com).

J Thorac Cardiovasc Surg 2020;160:396-7

$0022-5223 / \$ 36.00$

Copyright (c) 2019 by The American Association for Thoracic Surgery

https://doi.org/10.1016/j.jtcvs.2019.08.120

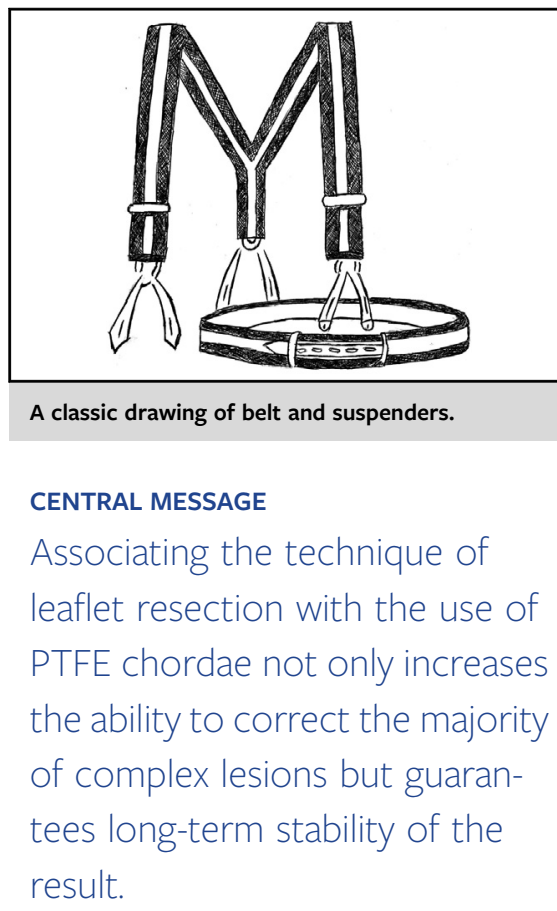

cases. An outstanding 5\% incidence of redo surgeries after 20 years clearly indicates a good strategy and a flawless execution. The authors claim that the use of PTFE chordae has greatly increased their ability to repair valves with multiple prolapses or with advanced myxomatous disease. This is certainly true, as the use of PTFE chordae allows a finetuning of small residual prolapse, and improved support of commissures or leaflet clefts. However, what is worth noticing is that in the great majority of cases, both leaflet resection and use of chordae were combined. Although in the whole population this combined approach was present in about $75 \%$ of the cases, it was used in almost $90 \%$ of the cases when both leaflets were involved. Given the long-term stability of the results, it seems logical to think that the double safety of a leaflet resection (the belt) associated with the use of PTFE chordae (the suspenders) becomes progressively more important when the anatomical situation is more complex. In any case, the lesson to be learned is that the use of PTFE chordae not only increases the possibility of repairing the great majority of patients with mitral regurgitation irrespective of their complex anatomical presentation, but more importantly, when combined with posterior leaflet resection, represents an important step to guarantee the best long-term results.

\footnotetext{
References

1. Carpentier A. Cardiac valve surgery - the "French correction". J Thorac Cardiovasc Surg. 1983;86:323-37.
} 
2. Vetter HO, Burack JH, Factor SM, Malacuso F, Frater RWM. Replacement of chordae tendineae of the mitral valve using the new expanded PTFE suture in sheep. In: Bodnar E, Yacoub M, eds. Biologic and Bioprosthetic Valves. New York: Yorke Medical Books; 1986:772-85.

3. Salvador L, Mirone S, Bianchini, Regesta T, Patelli F, Minniti G, et al. A 20-year experience with mitral valve repair with artificial chordae in 608 patients. J Thorac Cardiovasc Surg. 2008;135:1280-7.
4. Perier P, Hohenberger W, Lakew F, Batz G, Urbanski P, Zacher M, et al. Toward a new paradigm for the reconstruction of posterior leaflet prolapse: midterm results of the "respect rather than resect" approach. Ann Thorac Surg. 2008;86: 718-25.

5. David TE, David CM, Lafreniere-Roula M, Manlhiot C. Long-term outcomes of chordal replacement with expanded polytetrafluoroethylene sutures to repair mitral leaflet prolapse. J Thorac Cardiovasc Surg. 2020;160:385-94.e1.
See Article page 385 .

\section{Commentary: Expanded polytetrafluoroethylene cordal implantation for mitral valve repair: The founder series}

\author{
James S. Gammie, MD
}

In this report of the long-term clinical and echocardiographic outcomes of 746 patients undergoing repair of degenerative mitral valve disease with expanded polytetrafluoroethylene (ePTFE) cordal repair techniques, David and colleagues provide compelling evidence of the effectiveness and long-term durability of ePTFE-based mitral valve repair. ${ }^{1}$ This series provides valuable information for the student of mitral valve repair. The completeness and duration of clinical and echocardiographic follow-up are outstanding: $97 \%$ and $83 \%$, respectively, with a median echocardiographic follow-up of 10 years. Key takeaways include the observations of good long-term freedom from recurrent mitral regurgitation (MR), with a 5\% risk of moderate or severe recurrent MR at 5 years and $10 \%$ at 15 years; a low risk of reoperation, with $1.3 \%$ at 5 years and $3.4 \%$ at 15 years; and that artificial cordal repair enables maximal repair rates.

It is notable that Dr David, a pioneering mitral valve repair surgeon with extensive clinical experience, has progressively increased the number of artificial ePTFE cords

\footnotetext{
From the Division of Cardiac Surgery, Department of Surgery, University of Maryland Medical Center, Baltimore, Md.

Disclosures: Dr Gammie serves as a consultant for Edwards Lifesciences.

Received for publication Oct 30, 2019; accepted for publication Oct 30, 2019; available ahead of print Nov 22, 2019.

Address for reprints: James S. Gammie, MD, Division of Cardiac Surgery, Department of Surgery, University of Maryland Medical Center, 110, S Paca St, 7th Floor, Room 7-S-190, Baltimore, MD 21201 (E-mail: jsgammiemd@gmail.com).

J Thorac Cardiovasc Surg 2020;160:397-8

$0022-5223 / \$ 36.00$

Copyright (c) 2019 by The American Association for Thoracic Surgery

https://doi.org/10.1016/j.jtcvs.2019.10.191
}

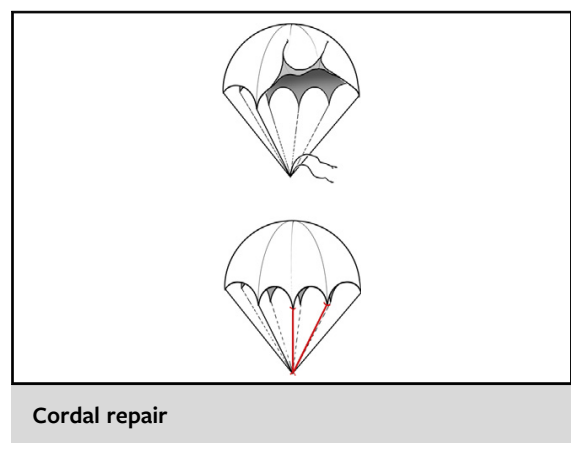

CENTRAL MESSAGE

Tirone David pioneered the use of ePTFE cords for mitral valve repair. The present series provides compelling evidence for the effectiveness and long-term durability of ePTFE-based mitral valve repair.

per case over time, from approximately 5 in the early years of this experience to 10 to 12 more recently. In fact, the overall median number of cords was 8 (or 4 pairs of cords), with implantation of 1 cord for each 2 to $3 \mathrm{~mm}$ of free leaflet edge. The "weaving" approach illustrated in the accompanying video enables the surgeon to efficiently implant a substantial number of cords and likely facilitates "autobalancing" of cordal segment lengths within a single suture. In the recent Society of Thoracic Surgeons adult cardiac surgery database experience, ePTFE cords were used in only one-third of repairs for degenerative leaflet prolapse, and among those patients undergoing ePTFE repairs, the median number of cordal pairs used was only $2 .^{2}$ It is likely that more cords are better than fewer cords.

The authors have identified isolated anterior leaflet prolapse as a risk factor for reoperation, as has been reported in other series. ${ }^{3}$ Precise cordal length adjustment and thus leaflet positioning is crucial to achieve adequate and 